\title{
REFINED GEOMETRIC INEQUALITIES BETWEEN TWO OR MORE TRIANGLES OBTAINED BY DEDUBLATION
}

\author{
RAZVAN ALIN SATNOIANU
}

\begin{abstract}
We study a class of inequalities between two or more triangles which extend the known metric relations between the elements of a single triangle. The common idea is that any quadratic type inequality between the elements of one triangle can have a "dedublated form" when written between the elements of two (or more) triangles with the optimal inequality being possible only when the triangles are similar. For example, we extend the well known quadratic form inequalities of Gerretsen [2, page 8] and give the new, dedublated form inequalities for the relations, which, in the case of a single triangle, correspond to the distances between the important points of the triangle such as circumcentre, incentre, orthocentre and the centre of mass.
\end{abstract}

\section{Mathematics subject classification (2000): 51M16.}

Key words and phrases: geometric triangle inequalities, inequalities between $N \geqslant 2$ triangles, quadratic forms, inequalities by dedublation, principle of the isosceles triangle.

\section{REFERENCES}

[1] D. Pedoe, Thinking geometrically, Amer. Math. Monthly 77 (1970), 711-721.

[2] D. S. Mitrinovic, J. E. PeCARIC And V. VoleneC, Recent Advances in Geometric Inequalities, Kluwer Academic, Dordrecht-Boston-London, 1989, 710 pages.

[3] L. CARLITZ, Some inequalities for two triangles, Mathem. Mag. 44 (1971), 43-44.

[4] J. ACZEL, Some general methods in the theory of functional equations in one variable. New applications of functional equations, Uspehi Mat. Nauk (N.S.), 3, 69 (1956), 3-68.

[5] M. S. Klamkin, Geometric inequalities via the polar moment of inertia, Mathem. Mag. 48 (1975), 44-46.

[6] RAZVAN A. SATNOIANU, A universal method to establishing geometric inequalities in triangles, American Mathematical Monthly, 108 (2001), 360-364

[7] R. A. Satnoianu, The universal principle of the isosceles triangle, Elem. der Mathem. 2004, in press.

[8] R. A. SATNOIANU, General power inequalities between the sides and the circumscribed and inscribed radii related to the fundamental triangle inequality, Math. Ineq. \& Appl. 5 (2002), 745-751.

[9] R. A. Satnoianu, Proposed problem 11022, American Mathematical Monthly, 110 (2003), 542.

[10] G. TsinTSIFAS, Problem 1114, Crux Math. 12 (1986), 26.

[11] A. OPPENHEIMER, Inequalities involving elements of triangles, quadrilaterals or tetrahedrals, Univ. Belgrade Publ. El. Fak. Ser. Mat. Fiz., 461-497 (1974), 257-263.

[12] W. J. BLundON, On certain polynomials associated with the triangle, Math. Mag. 36 (1963), 247-248.

[13] W. J. Blundon, Inequalities associated with the triangle, Canad. Math. Bull. 8 (1965), 615-626. 